\title{
Preparation and characterization of gum karaya hydrogel nanocomposite flocculant for metal ions removal from mine effluents
}

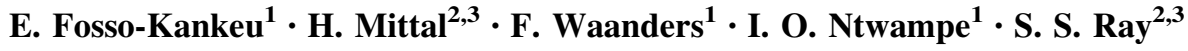

Received: 20 July 2015/Revised: 25 October 2015/Accepted: 30 November 2015/Published online: 14 December 2015

(C) Islamic Azad University (IAU) 2015

\begin{abstract}
This research paper reports the removal of heavy metal ions from mine effluents using the gum karaya (GK)-grafted poly(acrylamide-co-acrylic acid) incorporated iron oxide magnetic nanoparticles $\left(\mathrm{Fe}_{3} \mathrm{O}_{4} \mathrm{MNPs}\right)$ hydrogel nanocomposite [i.e., GK-cl-P(AAm-co-AA)/ $\mathrm{Fe}_{3} \mathrm{O}_{4}$ hydrogel nanocomposite] and inorganic coagulants such as polyferric chloride (af-PFCl), $\mathrm{Al}_{2}\left(\mathrm{SO}_{4}\right)_{3}, \mathrm{FeCl}_{3}$ and $\mathrm{Mg}(\mathrm{OH})_{2}$. The $\mathrm{Fe}_{3} \mathrm{O}_{4}$ MNPs were incorporated in the matrix of the hydrogel polymer of Gk-cl-P(AAm-co-AA) through the free radical graft co-polymerization technique using $N, N^{\prime}$-methylene-bis-acrylamide as the cross-linking agent. The graft co-polymerization of the $\mathrm{P}(\mathrm{AAm}-\mathrm{co}-\mathrm{AA})$ with $\mathrm{Gk}$ and the successful incorporation of the $\mathrm{Fe}_{3} \mathrm{O}_{4}$ MNPs within the hydrogel polymer matrix was evidenced using different characterization techniques such as FTIR, XRD, SEM and TEM. The performance of coagulants was evaluated by considering parameters such as turbidity removal, $\mathrm{pH}$ correction, metal removal and settling time. It was observed that the monomeric inorganic coagulants had a relatively poor performance compared to the organic coagulant, i.e., GK-cl-P(AAm-co-AA) $/ \mathrm{Fe}_{3} \mathrm{O}_{4}$ hydrogel nanocomposite. Most of the coagulants achieved maximum turbidity removal in the range of $67-99.5 \%$, but the
\end{abstract}

\section{E. Fosso-Kankeu}

kaelpfr@yahoo.fr

1 School of Chemical and Minerals Engineering, Faculty of Engineering, North West University, Potchefstroom Campus, Potchefstroom, South Africa

2 DST/CSIR National Centre for Nanostructured Materials, Council for Scientific and Industrial Research, Pretoria 0001, South Africa

3 Department of Applied Chemistry, University of Johannesburg, Doornfontein 2028, South Africa hydrogel nanocomposite showed the greatest reactivity by achieving the fastest floc formation rate and shortest optimum sedimentation time of $5 \mathrm{~min}(100 \%$ removal in $5 \mathrm{~min}$ ). The removal of metal followed the order $\mathrm{Pb}^{2+}>\mathrm{Cr}^{6+}>\mathrm{Ni}^{2+}$ with an optimum settling time of 15 min; more often, $\mathrm{Ni}^{2+}$ was poorly removed $(\leq 23.2 \%$ removal after $15 \mathrm{~min}$ ) from acidic mine water samples. Therefore, the synthesized hydrogel nanocomposite has shown great potential as a flocculant and adsorbent for the removal of suspended particles as well as heavy metal ions and can be used to improve the quality of mine effluents prior to discharge in the environment.

Keywords Suspended particles · Heavy metal ions · Mine water · Inorganic and organic polymers $\cdot$ Flocculation

\section{Introduction}

A host of techniques making use of inorganic coagulants are often applied for the removal of suspended solids from mine water and control of the $\mathrm{pH}$; however, problems related to the large amount of coagulants needed, excessive accumulation of sludge, the instability and breakage of aggregates, as well as the need of water conditioning have motivated investigation of alternative flocculants or coagulants (Rodriguez et al. 2003; Brostow et al. 2009; Yang et al. 2013). The efficiency of the flocculation process depends on the ability of coagulants and/or flocculants to adsorb on the fine residue particles bringing them together to form larger flocs which are likely to settle at a faster rate. Depending of their source, suspended particles may have different structures or properties and the selection of suitable coagulant will depend on the level of understanding of interactions between factors such as composition charge, 
particle size, shape and density. Suspended particles found in mine ponds often derived from streams of mill rejects or flotation tailings in the form of slurry and are likely to contain free metal ions which could contaminate the water system and affect aquatic life as well as pose a risk to human health. Therefore, water authorities around the world have tightened regulations regarding disposal of effluent loaded with metal ions. The removal of heavy metal ions from solution is conventionally achieved using chemical and physical methods which have a number of limitations including sludge formation and relatively high cost (Kefala et al. 1999; Ahalya et al. 2003; Fosso-Kankeu et al. 2009).

The inorganic coagulants commonly used are aluminum and iron salts. In comparison with monomeric form of salts, pre-polymerized inorganic coagulants have shown distinctive advantages including wide range of $\mathrm{pH}$ applications, relatively lower doses required for effective treatment, lower sensitivity to low water temperature and lower residual metal ion concentrations (Jiang and Graham 1998). Pre-polymerized inorganic coagulants of aluminum [polyaluminum chloride $(\mathrm{PACl})$ ] and ferric [polyferric sulfate (PFS) and polyferric chloride ( $\mathrm{PFCl})]$ ions have been intensively used recently for wastewater treatment (Dewolfe et al. 2003; Zhao et al. 2011). Coagulants based on the macromolecular compounds have a lot of advantages over the inorganic coagulants because their molar mass, chemical structure, charge density and the nature of their functional groups can be easily modified (Mittal et al. 2015a, b). The polymer-based coagulants can be further divided into the synthetic and natural polymer-based coagulants. Synthetic polymer-based coagulants have better property profile as compared to natural polymer-based coagulants, but at the same time, they are also associated with some serious drawbacks like toxicity and nonbiodegradability (Singh et al. 2000; Gaudreault et al. 2009). Moreover, it is very difficult to dispose the synthetic polymer-based coagulants after use so they cause a huge environmental burden. Therefore, in order to overcome this environmental problem, the natural biopolymer-based biodegradable coagulants/flocculants have been used by a number of researchers all over the world (Ghimici and Nichifor 2010, 2012; Ali 2010, 2012; Ghimici et al. 2012; Mittal et al. 2014a, b). Polysaccharide-based flocculants are environment-friendly and can be easily modified according to the end-use application. Recently, a great deal of effort has been made toward the development of flocculants with the advantages of both natural and synthetic polymers (Wan et al. 2007; Rani et al. 2010; Ho et al. 2010; Ghimici and Nichifor 2010, 2012; Ghimici et al. 2012; Mittal et al. 2013a). Different polysaccharides like pullulan-, dextran-, gum ghatti-, gum karaya- and gum xanthan-based polymeric materials and different nanomaterials have shown excellent potential as coagulants for the removal of different suspended particles from polluted waters. Furthermore, they have been also used as adsorbents for the removal of different metal ions and dyes from the aqueous solutions (Saleh et al. 2011; Gupta et al. 2011; Ghimici et al. 2012; Mittal et al. 2013a, b; Ghorai et al. 2014; Saravanan et al. 2013, 2014, 2015). Nanomaterials have also shown their potential as photo-catalysts (Saleh and Gupta 2011, 2012; Gupta et al. 2012; Saleh 2015). In our previous studies, the biodegradable graft co-polymers of gum ghatti showed good potential as flocculants and adsorbents for the adsorption of metal ions from the aqueous solutions (Mittal et al. 2013a, b, 2014a, b, 2015a, b).

Gum karaya (GK) is an anionic polysaccharide obtained from trees such as Sterculia urens, Sterculia villosa and Sterculia setigera growing in the Indian subcontinent and the North African countries, respectively (Weiping 2000). It is a highly branched complex polysaccharide consisting of D-galacturonic acid, D-galactose, L-rhamnose and Dglucuronic acid. The carbohydrate structure has a rhamnogalacturonan main chain consisting of $\alpha-(1 \rightarrow 4)$ linked D-galacturonic acid and $\alpha$ - $(1 \rightarrow 2)$-linked-L-rhamnosyl residues. The side chain is made up of $(1 \rightarrow 3)$-linked $\beta$ D-glucuronic acid or $(1 \rightarrow 2)$-linked $\beta$-D-galactose on the galacturonic acid unit where half of the rhamnose is substituted by $(1 \rightarrow 4)$-linked $\beta$-D-galactose (Anderson et al. 1982; Anderson and Wang 1994).

Therefore, keeping in view the structural diversity of the gum polysaccharides and their potential in water treatment applications, this study investigates the flocculation potential and adsorption behavior of GK-cl-P(AAm-co$\mathrm{AA} / \mathrm{Fe}_{3} \mathrm{O}_{4}$ hydrogel nanocomposite for the simultaneous removal of suspended particles and heavy metal ions from mine water in comparison with the performance of monomeric and pre-polymerized (af-PFCl) inorganic coagulants.

\section{Materials and methods}

\section{Methodology}

\section{Sample collection}

The sampling points were located at the underground and surface ponds within the premises of the mine. The water samples were carefully collected at the subsurface in polyethylene bottles, $1 \mathrm{~L}$ each of capacity; parameters such as $\mathrm{pH}$, temperature, electrical conductivity and turbidity were measured at the sites using portable Lovibond SensoDirect 150 multi-parameter water quality meter. The instruments were calibrated using original buffer solutions 
prior to the use in the field. The water samples were transported in cooler boxes containing ice packs and stored in the fridge overnight prior to the experiments. The mine water characteristics are reported in Table 1.

\section{Preparation of coagulants}

\section{Inorganic coagulants}

The chemicals used were of analytical grade; the stock solutions of $\mathrm{Al}_{2}\left(\mathrm{SO}_{4}\right)_{3}, \mathrm{FeCl}_{3}$ and $\mathrm{Mg}(\mathrm{OH})_{2}$ were prepared in order to obtain $1 \mathrm{~g} / \mathrm{L}$ of $\mathrm{Al}, \mathrm{Fe}$ and $\mathrm{Mg}$, respectively; this was done by diluting the salts of these metals into the demineralized water. The inorganic polymeric af- $\mathrm{PFCl}$ coagulant was synthesized by slowly adding $\mathrm{Ca}(\mathrm{OH})_{2}$ solution of $0.5 \mathrm{~mol} / \mathrm{L}$ to a $0.1 \mathrm{~mol} / \mathrm{L}$ solution of $\mathrm{FeCl}_{3}$ under constant steering speed at $350 \mathrm{rpm}$ at room temperature. A specific volume of $\mathrm{Ca}(\mathrm{OH})_{2}$ was added to $\mathrm{FeCl}_{3}$ solution till the predetermined basicity $\left(B=\left[\mathrm{OH}^{-}\right] /\right.$ $\left[\mathrm{Fe}^{3+}\right]$ ) was reached.

\section{Organic coagulant}

To synthesize the organic coagulant, i.e., GK-cl-P(AAmco-AA) $/ \mathrm{Fe}_{3} \mathrm{O}_{4}$ hydrogel nanocomposite, cross-linked network of poly(AAm-co-AA) with GK was prepared through free radical graft co-polymerization technique using KPS and $\mathrm{ABC}$ redox pair as an initiator and MBA as a crosslinking agent. The details of the synthesis of the Gk-cl$\mathrm{P}(\mathrm{AAm}-\mathrm{co}-\mathrm{AA})$ hydrogel polymer are given in our previous publication (Mittal et al. 2015a, b). Briefly, prior to grafting, a varied amount of the $\mathrm{Fe}_{3} \mathrm{O}_{4}$ MNPs $(25-100 \mathrm{mg}$ ) were added in $20 \mathrm{~mL}$ deionized water and sonicated for $4 \mathrm{~h}$ for a better dispersion of nanoparticles. After the sonication, GK $(1 \mathrm{~g})$ was added in the reaction mixture and stirred vigorously for the complete dissolution of gum in water. At this stage, a mixture of $30 \mathrm{mg}$ KPS and $20 \mathrm{mg}$ $\mathrm{ABC}$ was added in the reaction mixture and the temperature was maintained at $60{ }^{\circ} \mathrm{C}$. Fifty milligrams of MBA was added in the reaction mixture followed by the addition

Table 1 Recorded values of the physicochemical quality of water samples

\begin{tabular}{lcll}
\hline Sample ID & Turbidity $(\mathrm{NTU})$ & $\mathrm{pH}$ & $\mathrm{EC}(\mu \mathrm{s} / \mathrm{cm})$ \\
\hline $1 \mathrm{~A}$ & 56.31 & 2.24 & 4.6 \\
$2 \mathrm{~A}$ & 54.26 & 7.75 & 2 \\
$3 \mathrm{~A}$ & 2209.41 & 7.37 & 1.9 \\
$4 \mathrm{~A}$ & 333.07 & 7.69 & 1.8 \\
$5 \mathrm{~A}$ & 150.27 & 2.71 & 2.3 \\
\hline
\end{tabular}

of the mixture of AAm $(1 \mathrm{~g})$ and AA $(2.5 \mathrm{~mL})$ with constant stirring. After $3 \mathrm{~h}$, the reaction was stopped and cooled at room temperature. Homopolymers were removed by successive soxhlet extraction using acetone as solvent. Finally, the product was washed with $250 \mathrm{~mL}$ of acetone and dried in hot air oven at $40{ }^{\circ} \mathrm{C}$ till a constant weight was achieved. The selection of the best hydrogel nanocomposite for the rest of the studies was done on the basis of the maximum percentage swelling $\left(P_{\mathrm{s}}\right)$. Initially, $100 \mathrm{mg}$ of each hydrogel nanocomposite was added to $100 \mathrm{~mL}$ deionized water. After $24 \mathrm{~h}$, the samples were removed from the water, wiped gently to remove the surface water and weighed. The $P_{\mathrm{s}}$ value was calculated using the following equation:

$P_{\mathrm{s}}=\frac{W_{\mathrm{f}}-W_{\mathrm{i}}}{W_{\mathrm{f}}} \times 100$

where $W_{\mathrm{f}}$ and $W_{\mathrm{i}}$ are the weights of the swollen and dry hydrogel nanocomposites, respectively.

It was observed that the hydrogel nanocomposite with $50 \mathrm{mg}$ concentration of $\mathrm{Fe}_{3} \mathrm{O}_{4}$ MNPs gave the maximum swelling, so it was used for the rest of the studies (Table 2).

Characterization of the organic coagulant The incorporation of $\mathrm{Fe}_{3} \mathrm{O}_{4}$ MNPs in the cross-linked network of GKcl-P(AAm-co-AA) hydrogel was confirmed using different techniques such as BET, FTIR, SEM, TEM and XRD. $\mathrm{X}$-ray diffraction study of the samples was done by using Rigaku Ultima IV X-ray diffractometer employing $\mathrm{Cu} \mathrm{Ka}$ radiation of the wavelength of $1.5406 \AA$ with visible lights at $45 \mathrm{kV} / 40 \mathrm{~mA}$. The structural determination and the confirmation of grafting of $\mathrm{P}(\mathrm{AAm}-\mathrm{co}-\mathrm{AA})$ onto GK and incorporation of $\mathrm{Fe}_{3} \mathrm{O}_{4}$ MNPs within the polymer matrix were done through FTIR (PerkinElmer Spectrum 100 spectrometer) using KBR pellet method in the spectral range of $4000-400 \mathrm{~cm}^{-1}$ with a resolution of $4 \mathrm{~cm}^{-1}$. The changes in the morphology of GK after grafting and the polymer matrix after the incorporation of $\mathrm{Fe}_{3} \mathrm{O}_{4}$ MNPs were studied using scanning electron microscope (TESCAN, VEGA SEM) under a $20-\mathrm{kV}$ electron acceleration voltage coupled with energy-dispersive (EDX) for elemental analysis. As the samples were non-conducting in nature, these were coated with carbon for conductive

Table 2 Effect of the $\mathrm{Fe}_{3} \mathrm{O}_{4}$ MNPs concentration on the $P_{\mathrm{s}}$

\begin{tabular}{lll}
\hline S. No. & Amount of $\mathrm{Fe}_{3} \mathrm{O}_{4}$ MNPs $(\mathrm{mg})$ & $P_{\mathrm{s}}$ \\
\hline 1 & 25 & 1625 \\
2 & 50 & 2049 \\
3 & 75 & 1768 \\
4 & 100 & 1426 \\
\hline
\end{tabular}


metal coating and the scanning was concurred with the position of beam on the specimen for maintaining small size over a large distance relative to the specimen. Successful incorporation and variation in the size of $\mathrm{Fe}_{3} \mathrm{O}_{4}$ MNPs within polymer matrix was examined through JEOL JEM-2100F, field emission electron microscope with an accelerating voltage of $90 \mathrm{kV}$. Small pinch of sample was added in few milliliters of ethanol and sonicated for $30 \mathrm{~min}$. Two drops of sonicated suspension was transferred to the TEM grid and allowed to dry in ambient air. The increase in the BET surface area and porosity of the polymer matrix after the incorporation of $\mathrm{Fe}_{3} \mathrm{O}_{4}$ MNPs was studied by nitrogen adsorption-desorption measurements using Micromeritics, ASAP 2020, surface area and porosity analyzer.

\section{Jar test procedures}

The coagulation experiment was conducted using a jar test apparatus equipped with flat paddle impellers and was based on the conventional jar tests method with two mixing stages: a rapid mixing at $200 \mathrm{rpm}$ for $1 \mathrm{~min} 30 \mathrm{~s}$ after dosing followed by a slow mixing at $50 \mathrm{rpm}$ for $15 \mathrm{~min}$. The jar test was carried out with beakers of $500 \mathrm{~mL}$ capacity, and each beaker was filled with $300 \mathrm{~mL}$ sample. A fixed dosage considered in this study was $50 \mathrm{mg} / \mathrm{L}$ of the inorganic coagulants and $100 \mathrm{mg} / \mathrm{L}$ of the organic polymer. After the slow mixing, the samples were left to settle for a given period of time. After sedimentation, the sample was collected at $1 \mathrm{~cm}$ below the surface for water quality analysis.

\section{Settling time}

The settling time was an important variable considered to evaluate the rate of settling of flocs formed during the reaction of inorganic and organic coagulants with suspended particles. Samples were carefully withdrawn at $1 \mathrm{~cm}$ below the supernatant surface after $5,10,15$ and 60 min of sedimentation.

\section{Analysis}

The residual metal ions in the supernatant were quantified using the inductively coupled plasma optical emission spectrometer (ICP Expert II, Agilent Technologies 720 ICP-OES). To detect significant difference between metal removal rate at different settling times, Mann-Whitney test was performed and the difference was considered significant for values of $P<0.05$.

\section{Results and discussion}

\section{Characterization of the organic coagulant}

FTIR

The successful graft co-polymerization of $\mathrm{P}(\mathrm{AAm}-\mathrm{co}-\mathrm{AA})$ onto $\mathrm{Gk}$ and then the cross-linkage of the co-polymer [Gkcl-P(AAm-co-AA)] to the surface of $\mathrm{Fe}_{3} \mathrm{O}_{4}$ MNPs were evidenced using FTIR spectroscopy. FTIR spectrum of Gk, Gk-cl-P(AAm-co-AA) hydrogel polymer, uncoated $\mathrm{Fe}_{3} \mathrm{O}_{4}$ MNPs and Gk-cl-P(AAm-co-AA)/ $\mathrm{Fe}_{3} \mathrm{O}_{4}$ hydrogel nanocomposite is shown in Fig. 1. The FTIR spectrum of GK reveals absorption peaks at $3332 \mathrm{~cm}^{-1}$ assigned to the $-\mathrm{OH}$ stretching of the carbohydrates; $2938 \mathrm{~cm}^{-1}$, attributed to the $\mathrm{C}-\mathrm{H}$ stretching modes of $\mathrm{CH}_{2}$ groups; and 1715
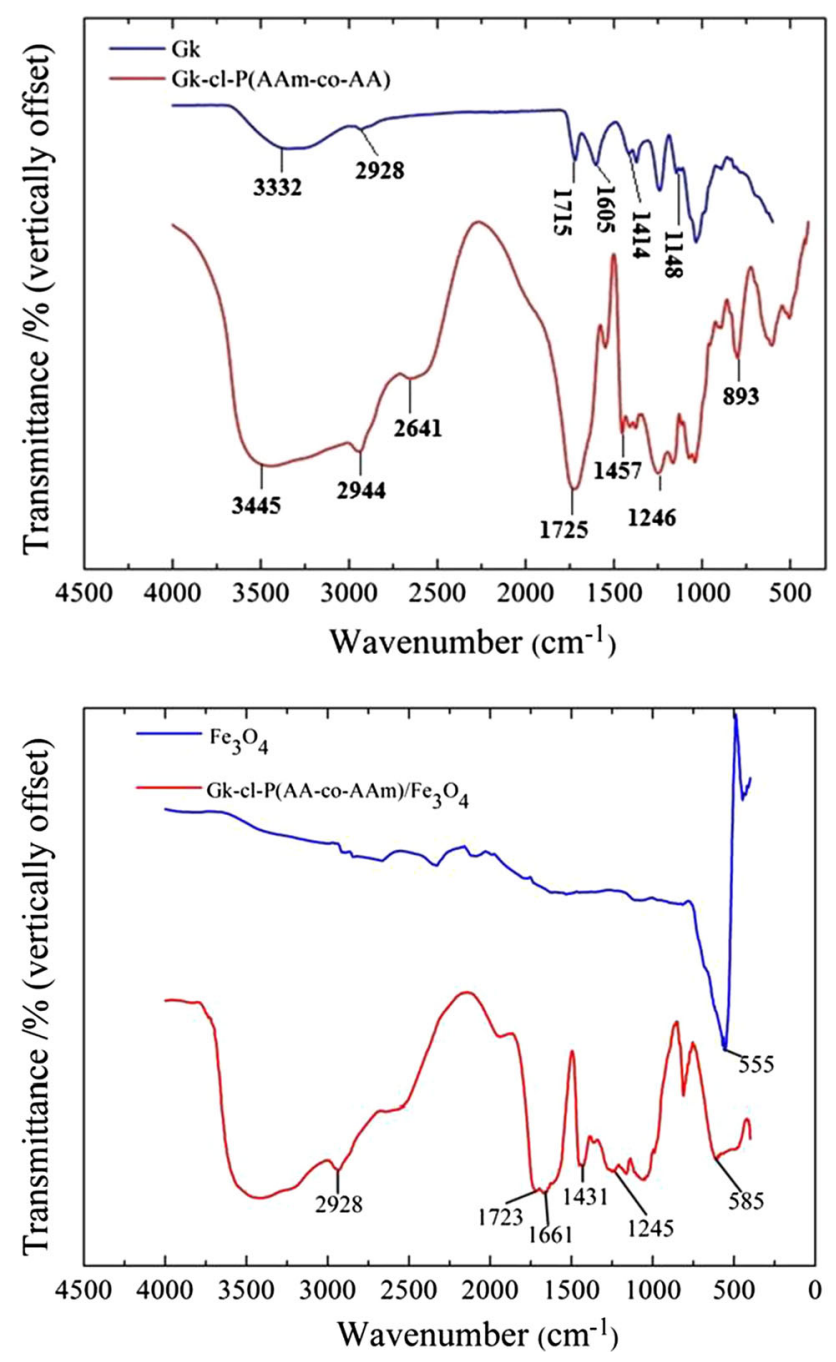

Fig. 1 FTIR spectra of Gk, Gk-cl-P(AAm-co-AA), $\mathrm{Fe}_{3} \mathrm{O}_{4}$ MNPs and Gk-cl-P(AAm-co-AA)/ $/ \mathrm{Fe}_{3} \mathrm{O}_{4}$ hydrogel nanocomposite 
and $1605 \mathrm{~cm}^{-1}$, due to the $\mathrm{C}=\mathrm{O}$ stretching vibrations of the free carboxylic acids and the methylated galacturonic acid esters of the gum. The absorption peak observed at $1148 \mathrm{~cm}^{-1}$ is attributed to the pyranose rings of the polysaccharides, and the peak at $1414 \mathrm{~cm}^{-1}$ is due to the $\mathrm{COO}^{-}$and the $\mathrm{C}-\mathrm{C}$ stretching of $-\mathrm{CH}_{2}$ scissoring (Fig. 1). In the FTIR spectrum of the GK-cl-P(AA-co-AAM) hydrogel polymer, the following peaks and assignments were observed: $3445 \mathrm{~cm}^{-1}$, due to $-\mathrm{OH}$ stretching vibrations; 2944 and $2641 \mathrm{~cm}^{-1}$, due to aliphatic $-\mathrm{CH}_{2}$ stretching vibrations; $1725 \mathrm{~cm}^{-1}$, due to the $\mathrm{C}=\mathrm{O}$ stretching in AA; $1457 \mathrm{~cm}^{-1}$, due to the amide $-\mathrm{NH}$ in-plane bending; $1246 \mathrm{~cm}^{-1}$, due to the amide $-\mathrm{CN}$ stretching vibration; and $893 \mathrm{~cm}^{-1}$, due to the amide $-\mathrm{OCN}$ deformation (Fig. 1). In the FTIR spectrum of uncoated $\mathrm{Fe}_{3} \mathrm{O}_{4}$ MPNs, characteristic adsorption peak of $\mathrm{Fe}-\mathrm{O}$ bond was observed at $555 \mathrm{~cm}^{-1}$, whereas after graft co-polymerization in Gk-cl-P(AAm-co-AA)/ $/ \mathrm{Fe}_{3} \mathrm{O}_{4}$ hydrogel nanocomposite, this particular peak was shifted at $585 \mathrm{~cm}^{-1}$. FTIR spectrum of Gk-cl-P(AAm-co-AA)/ $\mathrm{Fe}_{3} \mathrm{O}_{4}$ hydrogel nanocomposite showed peaks at $3417.87 \mathrm{~cm}^{-1}$ (-OH stretching vibration of carbohydrate), $2928 \mathrm{~cm}^{-1}$ (-OH stretching of acrylic acid), $1723 \mathrm{~cm}^{-1}$ ( $\mathrm{C}=\mathrm{O}$ stretching of acrylic acid), $1431 \mathrm{~cm}^{-1}\left(-\mathrm{CH},-\mathrm{CH}_{2}\right.$ and $-\mathrm{OH}$ in-plane bending in carbohydrates) and $1071.05 \mathrm{~cm}^{-1}$ (-CO stretching regions as complex bands resulting from $\mathrm{C}-\mathrm{O}$ and $\mathrm{C}-\mathrm{O}-\mathrm{C}$ stretching vibrations).

\section{$X R D$}

The XRD patterns of uncoated $\mathrm{Fe}_{3} \mathrm{O}_{4}$ MNPs and Gk-cl$\mathrm{P}(\mathrm{AAm}-\mathrm{co}-\mathrm{AA}) / \mathrm{Fe}_{3} \mathrm{O}_{4}$ hydrogel nanocomposite are shown in Fig. 2. The XRD pattern of uncoated $\mathrm{Fe}_{3} \mathrm{O}_{4}$ MNPs

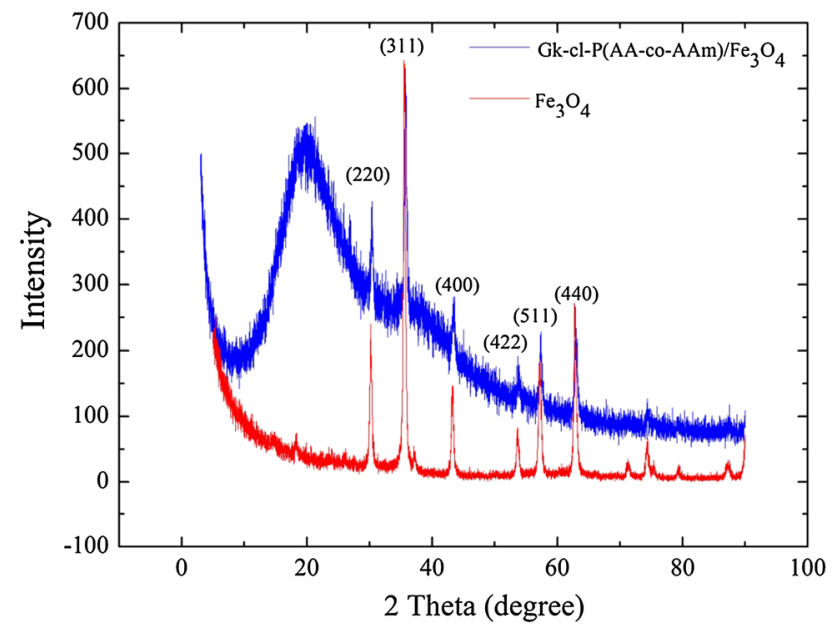

Fig. 2 Mineralogical composition of the organic coagulant depicted by XRD
(JCPDS 75-0033) showed the standard pattern with the diffraction peaks at (220), (311), (400), (422), (511) and (440) at $2 \theta$ scale. The XRD patterns of Gk-cl-P(AAm-co$\mathrm{AA} / \mathrm{Fe}_{3} \mathrm{O}_{4}$ hydrogel nanocomposite showed all the peaks observed in case of uncoated $\mathrm{Fe}_{3} \mathrm{O}_{4}$ MNPs which confirm the incorporation and uniform distribution of $\mathrm{Fe}_{3} \mathrm{O}_{4} \mathrm{MNPs}$ within Gk-cl-P(AAm-co-AA) polymer matrix with a little bit of reduced intensity. The peaks became slightly wider because of the coating of non-magnetic and amorphous Gk-cl-P(AAm-co-AA) hydrogel polymeric shell (Mittal et al. 2014a, b).

\section{Scanning electron microscopic studies}

The SEM images of Gk, Gk-cl-P(AAm-co-AA) and Gkcl-P(AAm-co-AA) $/ \mathrm{Fe}_{3} \mathrm{O}_{4}$ hydrogel nanocomposite are shown in Fig. 3. Very smooth, granular and homogeneous surface morphology was observed in the SEM image of Gk (Fig. 3a). Whereas this smooth surface became heterogeneous and very irregular and rough surface morphology was observed in case of the SEM of Gk-cl$\mathrm{P}$ (AAm-co-AA) hydrogel, this might be due to the crosslinking between different polymeric chains (Fig. 3b). The surface morphology of the polymeric matrix was also found to change after the incorporation of $\mathrm{Fe}_{3} \mathrm{O}_{4} \mathrm{MNPs}$, and a better matrix coherence was achieved (Fig. 3c). The surface morphology of Gk-cl-P(AAm-co-AA)/ $\mathrm{Fe}_{3} \mathrm{O}_{4}$ hydrogel nanocomposite was more coherent and near cocontinuous than the fibrillar surface of Gk-cl-P(AAm-coAA). The EDX spectra of the Gk-cl-P(AAm-co-AA)/ $\mathrm{Fe}_{3} \mathrm{O}_{4}$ hydrogel nanocomposite also showed peaks of $\mathrm{Fe}$ which further confirmed the incorporation of $\mathrm{Fe}_{3} \mathrm{O}_{4}$ MNPs within the cross-linked polymer matrix, i.e., Gk-clP(AAm-co-AA) (Fig. 3d).

\section{Transmission electron microscopy}

Figure 4 shows the typical TEM images of uncoated $\mathrm{Fe}_{3} \mathrm{O}_{4}$ MNPs and Gk-cl-P(AAm-co-AA)/ $/ \mathrm{Fe}_{3} \mathrm{O}_{4}$ hydrogel nanocomposite. TEM image of uncoated $\mathrm{Fe}_{3} \mathrm{O}_{4}$ MNPs showed well-shaped ellipsoidal and spherical magnetic nanoparticles (Fig. 4a). TEM of Gk-cl-P(AAm-co-AA)/ $\mathrm{Fe}_{3} \mathrm{O}_{4}$ hydrogel nanocomposite (Fig. $4 \mathrm{~b}$ ) also showed the presence of ellipsoidal and spherical magnetic nanoparticles which confirmed the incorporation of $\mathrm{Fe}_{3} \mathrm{O}_{4}$ MNPs in the three-dimensional cross-linked structure of Gk-cl-P(AAm-co-AA). The mean diameter of coated nanoparticles $(60 \mathrm{~nm})$ in hydrogel nanocomposite was found to be higher than that of uncoated $\mathrm{Fe}_{3} \mathrm{O}_{4}$ MNPs $(35 \mathrm{~nm})$. 

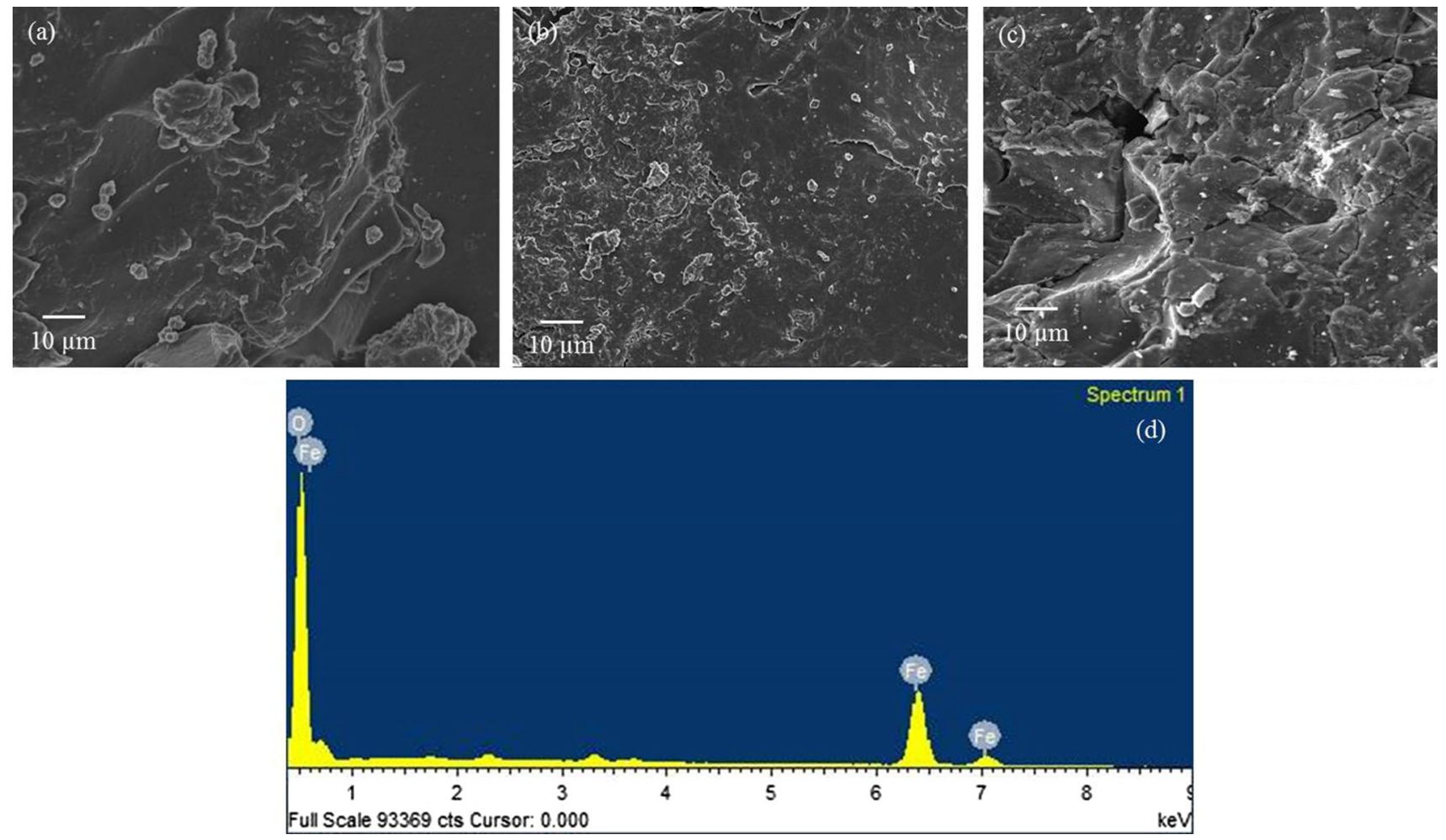

Fig. 3 Scanning electron microscopy of a GK, b GK-cl-P(AA-co-AAm), c GK-cl-P(AA-co-AAm)/Fe $\mathrm{O}_{4}$ and d EDX of GK-cl-P(AA-co-AAm)/ $\mathrm{Fe}_{3} \mathrm{O}_{4}$
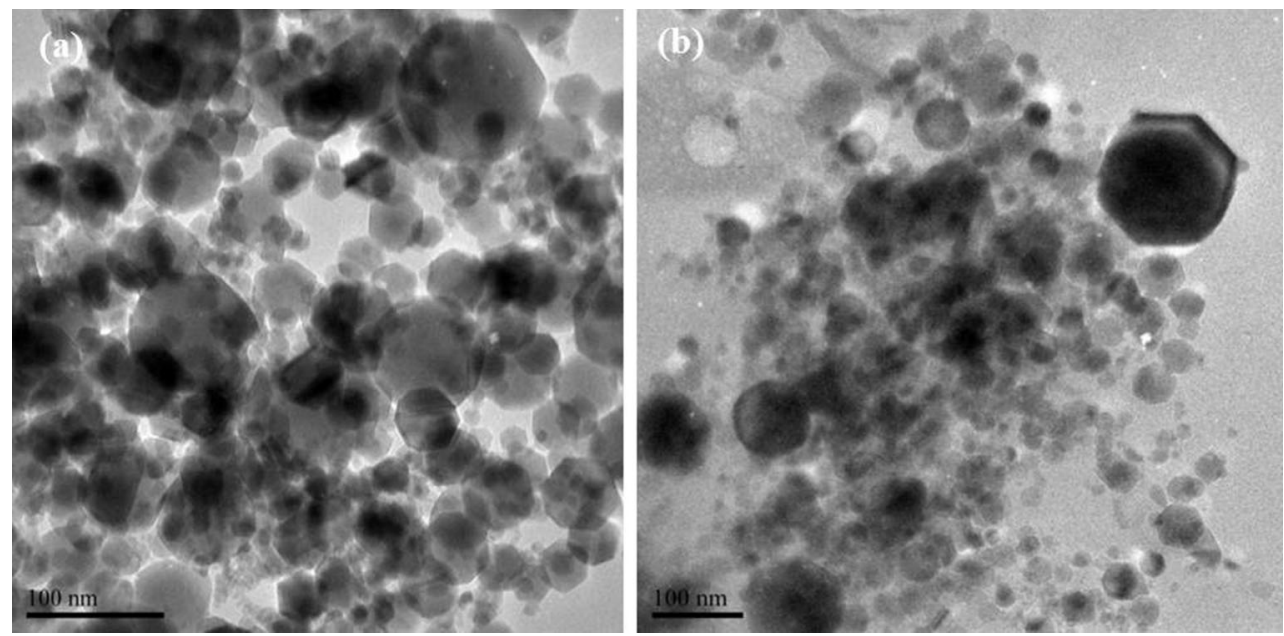

Fig. 4 Morphology of a $\mathrm{Fe}_{3} \mathrm{O}_{4}$ MNPs and b GK-cl-P(AA-co-AAM)/ $\mathrm{Fe}_{3} \mathrm{O}_{4}$ hydrogel nanocomposites identified with transmission electron microscope

\section{Brunauer-Emmett-Teller (BET) surface area}

The effect of the incorporation of $\mathrm{Fe}_{3} \mathrm{O}_{4}$ MNPs within the cross-linked polymer matrix of Gx-cl-PAA on its surface and pore volume was studied using BET analysis. BET surface area, pore volume and pore diameter of Gk-cl$\mathrm{P}(\mathrm{AAm}-\mathrm{co}-\mathrm{AA})$ hydrogel polymer were found to be $\quad 0.4658 \mathrm{~m}^{2} / \mathrm{g}, \quad 0.002458 \mathrm{~cm}^{3} / \mathrm{g}$ and $183.6915 \AA$, 


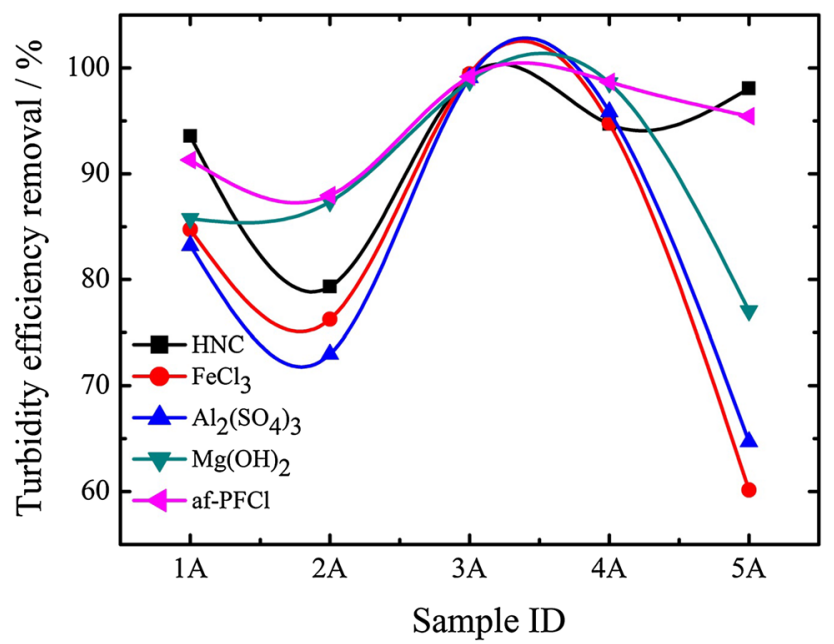

Fig. 5 Turbidity removal with inorganic and organic coagulants

respectively, and the values of these parameters were increased to $0.9845 \mathrm{~m}^{2} / \mathrm{g}, \quad 0.008473 \mathrm{~cm}^{3} / \mathrm{g}$ and $216.7254 \AA$, respectively, after the incorporation of $\mathrm{Fe}_{3} \mathrm{O}_{4}$ MNPs in the polymer matrix.

\section{Characteristics of water samples}

The $\mathrm{pH}$ of mine water samples ranged from acid to alkaline (from 2.24 to 7.75 ) as shown in Table 1; the ground water samples ( $1 \mathrm{~A}$ and $5 \mathrm{~A})$ were mostly acidic, while the surface water samples (2A, 3A and 4A) were mostly alkaline. The surface water samples were more turbid than the underground water, the turbidity ranging from 54.26 to 2209.41 NTU. The electrical conductivity values of the ground water samples were relatively higher than those of the surface water samples.

\section{Flocculation potential of coagulants}

A series of jar tests were conducted using five coagulants to reduce the turbidity in five mine water samples of different characteristics (Table 1). Initial experiments were conducted to estimate the optimum coagulant dosage; the fixed coagulant dosage was added to mine water solutions without amendment of $\mathrm{pH}$. The result in Fig. 5 shows unequal performance of coagulants, the turbidity removal ranging from 0 to $99.43 \%$. In general, alum $\left(\mathrm{Al}_{2}\left(\mathrm{SO}_{4}\right)_{3}\right)$ and $\mathrm{FeCl}_{3}$ showed a very poor turbidity removal capacity. The inorganic and the organic [GK-cl-P(AAm-co-AA)/ $\mathrm{Fe}_{3} \mathrm{O}_{4}$ ] polymers achieved higher turbidity removal, but the organic polymer was most effective in acidic mine water, while the inorganic polymer performed better in alkaline

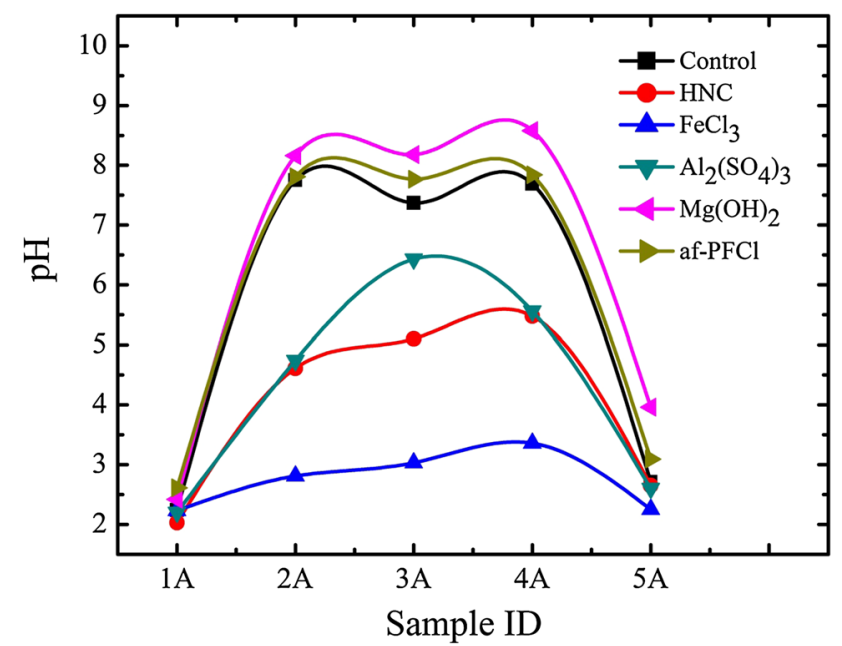

Fig. $6 \mathrm{pH}$ correction by inorganic and organic coagulants

mine water. The monomeric coagulants were generally very ineffective in the removal of turbidity from acidic mine water; this dependence on $\mathrm{pH}$ was previously reported by other researchers (Jiang and Graham 1998; Gao et al. 2011). Co-polymers of acrylamide and sodium acrylate are reported to be non-anionic and therefore are likely to show the greatest activity at $\mathrm{pH}$ of 4 and below (Connelly and Richardson 1984).

An advantage of the treatment of water with the inorganic polymer (af-PFCl) is that the branches of the polymer are adsorbed onto different colloidal particles, interlocking with one another and thereby leading to the formation of a settleable mass which improves turbidity removal (Peavy et al. 1985). The $\mathrm{pH}$ range in the batch samples falls within a range $2.35-8.43$, which is suitable for the development of various hydrolysis species. Each species has an area of dominance with some overlap as explained by Peavy et al. (1985). $\mathrm{Fe}(\mathrm{OH})^{2+}$ is the first species to form due to decreasing concentration of $\mathrm{Fe}^{3+}$ covering an area in the $\mathrm{pH}$ range $1-5$. It is followed by $\mathrm{Fe}(\mathrm{OH})_{2}^{+}$which falls within $\mathrm{pH}$ range 2-7 and follows $\mathrm{Fe}(\mathrm{OH})_{3(\text { aq })}$ which covers $\mathrm{pH}$ of $4-8$. The last species is $\mathrm{Fe}(\mathrm{OH})_{4}^{-}$which covers $\mathrm{pH}$ range 4-14. According to turbidity removal and corresponding $\mathrm{pH}$ values in the raw samples $1 \mathrm{~A}$ and $5 \mathrm{~A}$, it is evident that adsorption occurs through charge neutralization. Charge neutralization occurs when the $\mathrm{pH}$ is acidic where excess positive charges neutralize negative charges in colloidal particles. Alkaline batch samples are conducive for the existence of ferric hydroxide species as they have a minimum solubility in a $\mathrm{pH}$ range of $7-10$, which gives them more flexibility during hydrolysis (Binnie et al. 2003). 

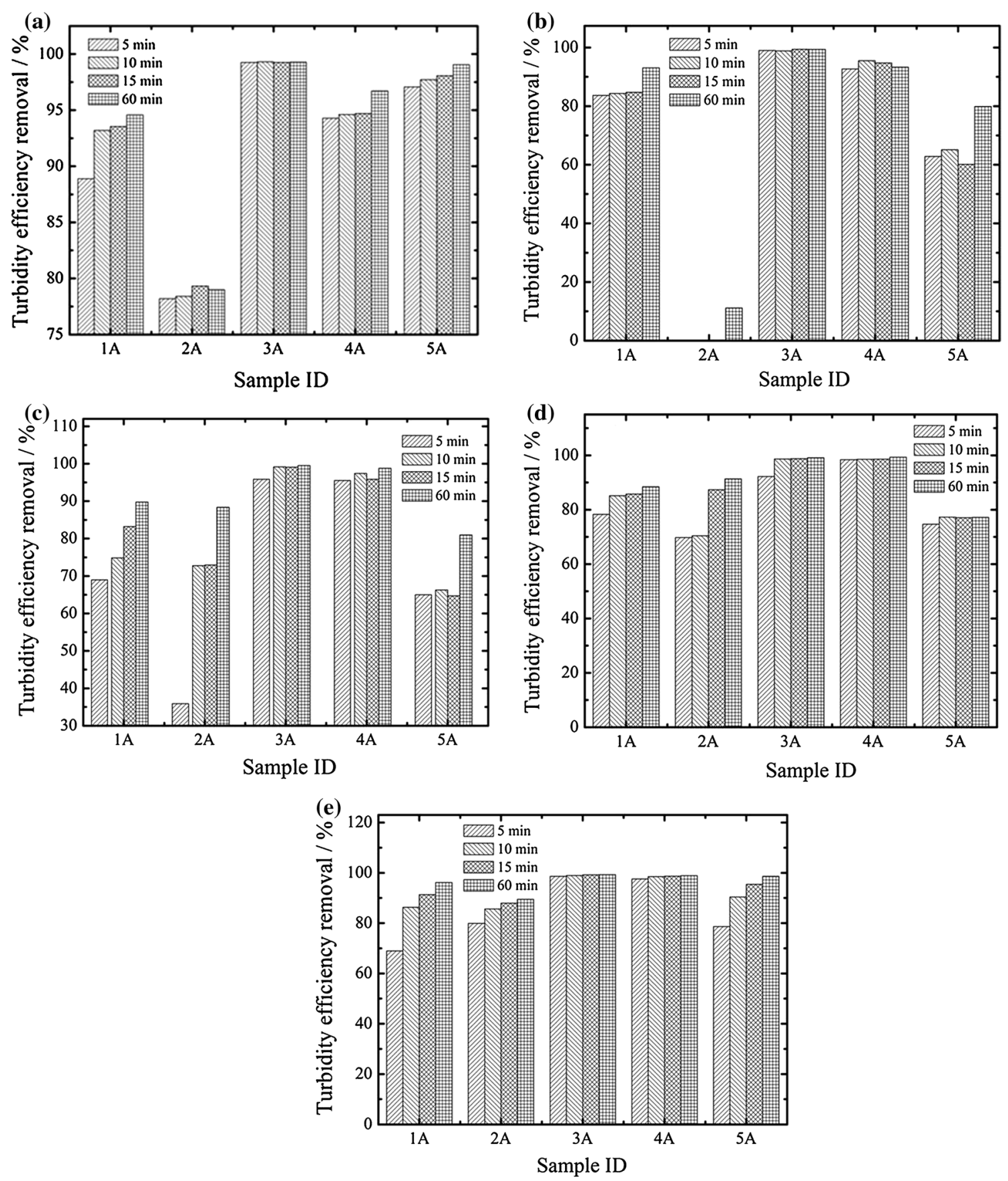

Fig. 7 Effect of aging on the turbidity removal efficiency of a (GK-cl-P(AAm-co-AA)/ $\left.\mathrm{Fe}_{3} \mathrm{O}_{4}\right), \mathbf{b} \mathrm{FeCl}_{3}, \mathbf{c ~} \mathrm{Al}_{2}\left(\mathrm{SO}_{4}\right)_{3}, \mathbf{d ~ M g}(\mathrm{OH})_{2}, \mathbf{e}$ af-PFCl

\section{Correction of $\mathrm{pH}$ by coagulants}

The treatment of waste water especially acid mine drainage (AMD) focuses among other on the correction of $\mathrm{pH}$; hence, in most cases two or more coagulants are used to address turbidity removal and $\mathrm{pH}$ correction; it will be ideal to have a coagulant that can do both in a single step saving, therefore, time and money. The divergence of $\mathrm{pH}$ 
in our mine water samples offers a good opportunity to investigate the potential of our coagulants to adjust the $\mathrm{pH}$ to acceptable level. The results in Fig. 6 show that our coagulants had little or no effect on $\mathrm{pH}$ in acidic mine water; in sample $5 \mathrm{~A}, \mathrm{Mg}(\mathrm{OH})_{2}$ contributed to increase the $\mathrm{pH}$ from 2.71 to around 4. Most of the coagulants especially $\mathrm{FeCl}_{3}$ contributed to change alkaline $\mathrm{pH}$ to acidic; however, $\mathrm{Mg}(\mathrm{OH})_{2}$ increased the $\mathrm{pH}$ by around 0.5 under such conditions, while af-PFCl did not affect the $\mathrm{pH}$.

\section{Optimization of flocculation}

Flocs formation, growth and sedimentation are time dependent; the potential of floc formation and growth is mostly affected by the coagulant type, ionic strength, water $\mathrm{pH}$, suspended particles, coagulant dilution, shear, molecular weight and process conditions. The reactivity of the coagulant through adsorption and neutralization promotes formation of bigger and stable flocs likely to settle at faster rate. The settling time is an important parameter to consider for the optimization of the flocculation process.

Figure 7a shows the turbidity removal by the organic polymer [GK-cl-P(AAm-co-AA)/ $\mathrm{Fe}_{3} \mathrm{O}_{4}$ ] over a period of time $(5,10,15$ and $60 \mathrm{~min})$; it is observed that except for the samples $2 \mathrm{~A}$ and $3 \mathrm{~A}$ where the turbidity removal remains stable after $5 \mathrm{~min}$, there is improvement in turbidity removal with the increase in time in samples $1 \mathrm{~A}, 4 \mathrm{~A}$ and 5A. However, the little increase in turbidity removal over time suggests that our organic polymer has a quick reactivity with suspended particles resulting in floc growth at faster rate and hence the rapid sedimentation; in this case, an optimum sedimentation time could be considered to be $5 \mathrm{~min}$. The effect of time on the turbidity removal by $\mathrm{FeCl}_{3}$ was inconsistent in samples $4 \mathrm{~A}$ and $5 \mathrm{~A}$ (Fig. 7b), but the general trend also suggests a rapid sedimentation achieved after $5 \mathrm{~min}$.

The coagulant alum $\left(\mathrm{Al}_{2}\left(\mathrm{SO}_{4}\right)_{3}\right)$ exhibited a relatively slow and poor reactivity during the treatment of samples $1 \mathrm{~A}, 2 \mathrm{~A}$ and $5 \mathrm{~A}$ judging by the low turbidity removal after each sedimentation time $(5,10,15$ and $60 \mathrm{~min})$, corresponding to $68.99-74.84-83.21-89.75 \% \quad$ (1A) and $35.88-72.779-72.963-88.35 \% \quad$ (2A), respectively (Fig. 7c). Although the quicker reactivity was achieved in samples $3 \mathrm{~A}$ and $4 \mathrm{~A}$, the performance of alum was mostly poor. The coagulant $\mathrm{Mg}(\mathrm{OH})_{2}$ exhibited almost a similar performance as alum with optimum turbidity removal only after $10 \mathrm{~min}$ in samples $1 \mathrm{~A}$ and $3 \mathrm{~A}$ and $15 \mathrm{~min}$ in sample $2 \mathrm{~A}$.
Except for samples $3 \mathrm{~A}$ and $4 \mathrm{~A}$, it was observed that the turbidity removal efficiency of af- $\mathrm{PFCl}$ was improved with aging especially in acidic mine water samples (1 A and 5A) (Fig. 7e); in this case, prolonged retention time for settling enables the formation of larger flocs during nucleation to effectively reduce turbidity. Studying the impact of $\mathrm{pH}$ on floc structure with polyferric chloride (PFCl) as coagulant, Cao et al. (2011) came to realize that the formation of flocs was much slower when coagulation condition was acidic.

\section{Simultaneous removal of metals from mine water}

\section{Effect of settling time}

The removal of metals can be easily predicted when using synthetic solutions; it is, however, more complex for turbid solutions, as more than one mechanisms including charge neutralization, enmeshment and possibly hydroxylation-precipitation may be involved in the removal of metals. The type of coagulant and metal is therefore likely to determine the flocculation mechanism as well as the rate of agglomeration of flocs and settling; in this study, the metal removal capacities of four coagulants were evaluated by considering the settling speed. Figure $8 \mathrm{a}-\mathrm{e}$ shows that there was an increase in removal rate with time, but the optimum time recorded using each coagulant was 15 min after which no significant removal occurred. However, the removal capacity did vary among the coagulants. Better coagulants are likely to effectively remove the metal at a faster rate; it was observed that the organic polymer nanocomposite [GK-cl-P(AAm-co-AA)/ $\left.\mathrm{Fe}_{3} \mathrm{O}_{4}\right]$ performed better than the other coagulants. The $\mathrm{pH}$ of the solution is likely to affect the net charges of the elements present, but most importantly a high $\mathrm{pH}$ may lead to metal hydroxide precipitation which is different to the removal as a result of coagulation and flocculation; removal of metals from acidic and non-acidic mine solutions was therefore important to evaluate the exact mechanism of metal removal. The results did show that nickel was much soluble in acidic solutions (samples 1A and $5 \mathrm{~A}$ ). According to the hydroxocomplex stability, $\mathrm{Ni}^{2+}$ is more soluble than $\mathrm{Cr}^{6+}$ and $\mathrm{Pb}^{2+}$, and in previous works $\mathrm{Ni}^{2+}$ removal was achieved at relatively high $\mathrm{pH}$; using tannin-based flocculant agent, Heredia and Martin (2009) required an increase in $\mathrm{pH}$ to 9 for optimum removal of $\mathrm{Ni}^{2+}$ while in separate study, using polyampholyte chitosan derivatives (-N-carboxyethylated chitosans), Bratskaya et al. (2009) observed a $60 \%$ removal 

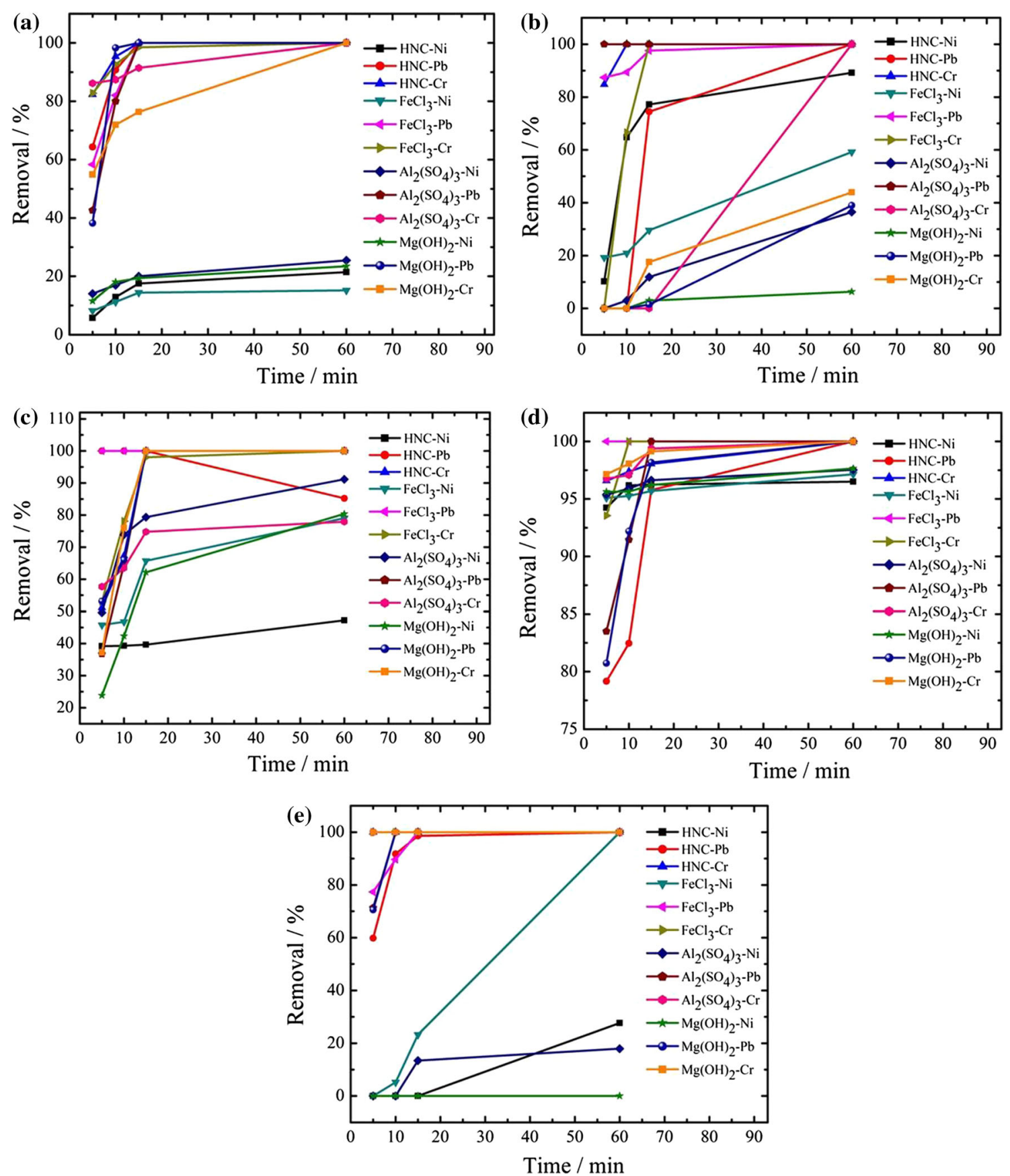

Fig. 8 Influence of settling time on metal ions removal from various mine effluents samples: a sample $1 \mathrm{~A}$, b sample $2 \mathrm{~A}$, c sample $3 \mathrm{~A}$, d sample $4 \mathrm{~A}$, e sample $5 \mathrm{~A}$

of $\mathrm{Ni}^{2+}$ at $\mathrm{pH} 7.5$, but better removal of $\mathrm{Ni}^{2+}$ from wastewaters was achieved at $\mathrm{pH} 9$ which was ascribed to increase in complexation degree of the metal in hydroxycomplexes. In this study, the removal of $\mathrm{Cr}^{6+}$ and $\mathrm{Pb}^{2+}$ was, however, not affected by the $\mathrm{pH}$, and they were effectively removed even below their $\mathrm{pH}$ precipitation zone; the removal in this case was likely due to a combination hydroxylation and colloids entrapment in the case of inorganic flocculants, while in the case of the organic polymer which has a net negative charge, surface charged neutralization and bridging may have also played a role. The metals of interest being of positive charge 
Fig. 9 Schematic diagram of the adsorption of metal ions onto the organic flocculant

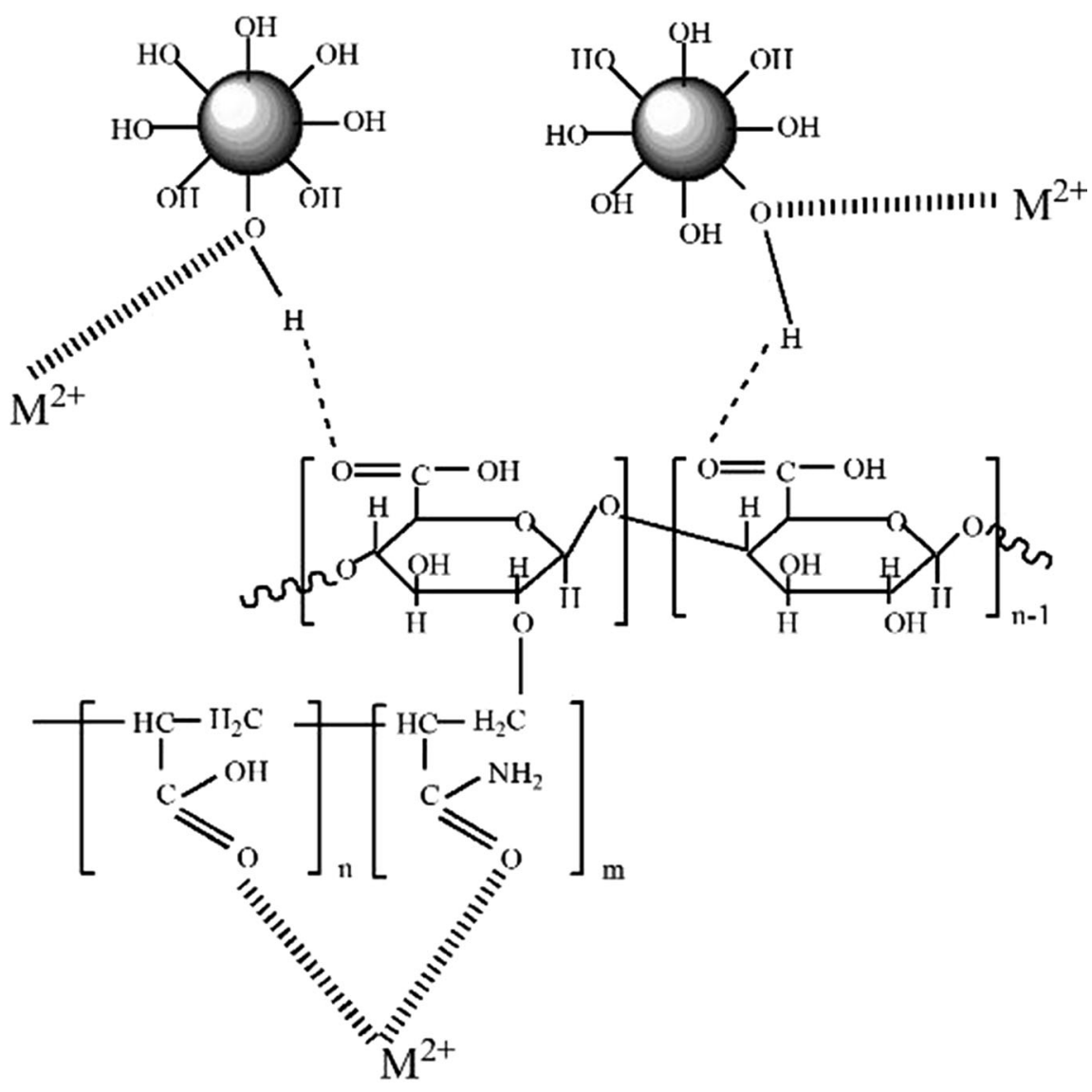

Where, $\mathrm{M}^{2+}=\mathrm{Pb}^{+2}, \mathrm{Ni}^{+2}$

Table 3 Compliance of residual metals concentrations to SABS (2005) drinking water quality guideline

\begin{tabular}{|c|c|c|c|c|c|c|c|c|c|c|c|c|c|c|c|c|}
\hline \multirow[t]{2}{*}{ Flocculants } & \multirow[t]{2}{*}{ Metals } & \multicolumn{3}{|c|}{ Sample 1A } & \multicolumn{3}{|c|}{ Sample 2A } & \multicolumn{3}{|c|}{ Sample 3A } & \multicolumn{3}{|c|}{ Sample 4A } & \multicolumn{3}{|c|}{ Sample 5A } \\
\hline & & $\% \mathrm{R}$ & GF & $\mathrm{P}$ & $\% \mathrm{R}$ & GF & $\mathrm{P}$ & $\% \mathrm{R}$ & GF & $\mathrm{P}$ & $\% \mathrm{R}$ & GF & $\mathrm{P}$ & $\% \mathrm{R}$ & GF & $\mathrm{P}$ \\
\hline \multirow[t]{3}{*}{ CK } & $\mathrm{Ni}$ & 17.6 & No & 0.126 & 77.2 & No & 0.139 & 39.6 & No & 0.748 & 96.3 & No & 0.076 & 0 & No & 0.382 \\
\hline & $\mathrm{Pb}$ & 100 & Yes & & 74.5 & No & & 100 & Yes & & 95.8 & Yes & & 98.6 & Yes & \\
\hline & $\mathrm{Cr}$ & 100 & Yes & & 100 & Yes & & 100 & Yes & & 98 & Yes & & 100 & Yes & \\
\hline \multirow[t]{3}{*}{$\mathrm{FeCl}_{3}$} & $\mathrm{Ni}$ & 14.4 & No & & 29.6 & No & & 65.7 & No & & 95.7 & No & & 23.2 & No & \\
\hline & $\mathrm{Pb}$ & 100 & Yes & & 97.6 & Yes & & 100 & Yes & & 100 & Yes & & 100 & Yes & \\
\hline & $\mathrm{Cr}$ & 98.5 & Yes & & 100 & Yes & & 98 & Yes & & 100 & Yes & & 100 & Yes & \\
\hline \multirow[t]{3}{*}{$\mathrm{Al}_{2}\left(\mathrm{SO}_{4}\right)_{3}$} & $\mathrm{Ni}$ & 20 & No & & 11.8 & No & & 79.3 & No & & 96.6 & No & & 13.4 & No & \\
\hline & $\mathrm{Pb}$ & 100 & Yes & & 100 & Yes & & 100 & Yes & & 100 & Yes & & 100 & Yes & \\
\hline & $\mathrm{Cr}$ & 91.5 & Yes & & 0 & Yes & & 74.8 & Yes & & 99.4 & Yes & & 100 & Yes & \\
\hline \multirow[t]{3}{*}{$\mathrm{Mg}(\mathrm{OH})_{2}$} & $\mathrm{Ni}$ & 19.4 & No & & 3 & No & & 62.2 & No & & 96.2 & No & & 0 & No & \\
\hline & $\mathrm{Pb}$ & 100 & Yes & & 1.4 & No & & 100 & Yes & & 98.2 & Yes & & 100 & Yes & \\
\hline & $\mathrm{Cr}$ & 76.3 & No & & 17.5 & Yes & & 100 & Yes & & 99.1 & Yes & & 100 & Yes & \\
\hline
\end{tabular}

$G F$ guideline fitness, $R$ removal, $P p$ value 
which is opposite sign to the charge of the organic polymer could be attracted to the surface of the latter according to the principle of surface charged neutralization (Fig. 9). On the other hand, the long chain of the organic polymer tends to form a loop that attaches to other particles in water, resulting in bridging of particles together (Kolya and Tripathy 2013). Among all the metals, $\mathrm{Pb}^{2+}$ was easily removed from solutions; it has been reported (Fosso-Kankeu and Waanders 2014) that higher atomic weight leads to preferential binding of metal to the adsorbent material, and furthermore, binding affinity of metal to the adsorbent increases with the electronegativity of the metal (Fosso-Kankeu et al. 2014). In this case, $\mathrm{Pb}^{2+}$ has a higher atomic weight and electronegativity compared to $\mathrm{Cr}^{6+}$ and $\mathrm{Ni}^{2+}$, which may partly explain the higher removal of $\mathrm{Pb}^{2+}$ compared to other metals.

\section{Achievement of acceptable level of metal ions in water}

Evaluation of the optimum time of settling was done by statistical comparison with metal removal rate at the various settling time considered, and it was observed that higher metal removal was achieved between 15 and 60 min, while there was no significant difference $[p$ values 0.126 (sample 1A), 0.139 (sample 2A), 0.748 (sample 3A), 0.076 (sample 4A) and 0.382 (sample 5A)] between the two settling times (Table 3). Therefore, the optimum time of $15 \mathrm{~min}$ was considered to evaluate the water quality fitness to the South African Bureau of Standard guideline (2005) for drinking water.

Heavy metal ions such as $\mathrm{Cr}^{6+}, \mathrm{Pb}^{2+}$ and $\mathrm{Ni}^{2+}$ are generally highly toxic and can be responsible for the disequilibrium of the ecosystem in the aquatic environment as well as impacting human life. It is therefore important to ensure effective removal of metals from aqueous solution to a safer level, meeting the available guideline. After 15-min settling time, it was observed that in most of the cases the recommended values were met; however, as observed above, $\mathrm{Ni}^{2+}$ was hardly removed from the water and therefore remains in solutions at concentrations above the acceptable value.

\section{Conclusion}

The use of the real solutions from mine sites allowed to investigate in this study the impact of $\mathrm{pH}$ on the coagulation efficiency; this enabled to distinctively highlight the behavior of inorganic as well as organic coagulants during turbidity removal. It is therefore important to mention that the solution $\mathrm{pH}$ significantly influences turbidity removal efficiency as well as the sedimentation rate, but depending of the type of coagulant, the response to this influence varied. It is observed that the organic coagulant [GK-cl$\left.\mathrm{P}(\mathrm{AAm}-\mathrm{co}-\mathrm{AA}) / \mathrm{Fe}_{3} \mathrm{O}_{4}\right]$ and the inorganic polymer performed better in a wide range of $\mathrm{pH}$, while monomeric inorganic coagulants performed well under alkaline condition. The coagulants used in this study did not correct the acidic $\mathrm{pH}$ to recommended value. The removal of metal ions during flocculation process was achieved after an optimum settling time of 15 min reaching the SABS's (2005) recommended values in drinking water for $\mathrm{Pb}^{2+}$ and $\mathrm{Cr}^{6+}$, but not $\mathrm{Ni}^{2+}$ which was poorly removed especially in acidic solutions.

Acknowledgments The authors are grateful to the sponsor from the North-West University and the National Research Foundation (NRF) in South Africa and the contribution of Mr N Lemmer of the Laboratory of Minerals Processing in the School of Chemical Engineering, North-West University. The authors are also grateful to the National Research Foundation (NRF), South Africa, for awarding a postdoctoral research fellowship. The authors also thank the University of Johannesburg, the Department of Science and Technology and the Council for Scientific and Industrial Research for financial support.

\section{References}

Ahalya N, Ramachandra TV, Kanamadi RD (2003) Biosorption of heavy metal ions. Res J Chem Environ 7:71-78

Ali I (2010) The quest for active carbon adsorbent substitutes: inexpensive adsorbents for toxic metal ions removal from wastewater. Sep Purif Rev 39:95-171

Ali I (2012) New generation adsorbents for water treatment. Chem Rev 112:5073-5091

Anderson DMW, Wang W (1994) The tree exudate gums permitted in foodstuffs as emulsifiers, stabilisers and thickeners. Chem Ind For Prod 14:73-84

Anderson DMW, Mcnab CNB, Anderson CG, Braown PM, Pringuer MA (1982) Gum exudates from the genus sterculia (gum karaya). Int Tree Crops J 2:147-154

Binnie C, Kimber M, Smethurst G (2003) Basic water treatment, 3rd edn. MPG Books, Bodmin

Bratskaya SY, Pestov AV, Yatluk YG, Avramenko VA (2009) Heavy metal ions removal by flocculation/precipitation using $\mathrm{N}-(2-$ carboxyethyl) chitosans. Colloids Surf A: Physicochem Eng Asp 339:140-144

Brostow W, Lobland HEH, Pal S, Singh RP (2009) Polymeric flocculants for wastewater and industrial effluent treatment. J Mater Educ 31(3-4):157-166

Cao B, Gao B, Liu X, Wang M, Yang Z, Yue Q (2011) The impact of $\mathrm{pH}$ on floc structure characteristic of polyferric chloride in a low DOC and high alkalinity surface water treatment. Water Res 45:6181-6188

Connelly LJ, Richardson PF (1984) Coagulation and Flocculation in the Mining Industry. In: Symposium on solids/liquids separation 
and mixing in industrial practice, AIChE (Pittsburgh Section), 1984

Dewolfe J, Dempsey B, Taylor M, Potter JW (2003) Guidance manual for coagulant changeover. American Water Works Association Press, Denver, pp 5-6

Fosso-Kankeu E, Waanders F (2014) Metal ions adsorption affinity of clay materials from the North West province of South Africa. An interdisciplinary response to mine water challenges. In: Sui W, Sun Y, Wang C (eds) International mine water conference, August 2014, Xuzhou, China, China University of Mining and Technology Press, Xuzhou, pp 374-378. ISBN: 978-7-56462437-8

Fosso-Kankeu E, Mulaba-Bafubiandi A, Mamba BB, Barnard TG (2009) Mitigation of $\mathrm{Ca}, \mathrm{Fe}$, and $\mathrm{Mg}$ loads in surface waters around mining areas using indigenous microorganism strains. J Phys Chem Earth 34:825-829

Fosso-Kankeu E, Mulaba-Bafubiandi AF, Barnard TG (2014) Establishing suitable conditions for metals recovery from metal saturated Bacillaceae bacterium using experimental design. Int Biodeterior Biodegradation 86:218-224

Gao B, Liu B, Chen T, Yue Q (2011) Effect of aging period on the characteristics and coagulation behavior of polyferric chloride and polyferric-polyamine composite coagulant for synthetic dying wastewater treatment. J Hazard Mater 187:413-420

Gaudreault RN, Cesare ND, Weitz D, van de Ven TGM (2009) Flocculation kinetics of precipitated calcium carbonate. Colloids Surf A: Physicochem Eng Asp 340:56-65

Ghimici L, Nichifor M (2010) Novel biodegradable flocculanting agents based on cationic amphiphilic polysaccharides. Bioresour Technol 101:8549-8554

Ghimici L, Nichifor M (2012) Flocculation by cationic amphiphilic polyelectrolyte: relating efficiency with the association of polyelectrolyte in the initial solution. Colloids Surf A: Physicochem Eng Asp 415:142-147

Ghimici L, Constantin M, Fundueanu G (2012) Novel biodegradable flocculanting agents based on pullulan. J Hazard Mater 181:351-358

Ghorai S, Sarkar A, Raoufi M, Panda AB, Schönherr H, Pal S (2014) Enhanced removal of methylene blue and methyl violet dyes from aqueous solution using a nanocomposite of hydrolyzed polyacrylamide grafted xanthan gum and incorporated nanosilica. ACS Appl Mater Interfaces 6:4766-4777

Gupta VK, Agarwal S, Saleh TA (2011) Synthesis and characterization of alumina-coated carbon nanotubes and their application for lead removal. J Hazard Mater 185:17-23

Gupta VK, Jain R, Mittal A, Saleh TA, Nayak A, Agarwal S, Sikarwar S (2012) Photo-catalytic degradation of toxic dye amaranth on $\mathrm{TiO}_{2} / \mathrm{UV}$ in aqueous suspensions. Mater Sci Eng, C 32:12-17

Heredia JB, Martin JS (2009) Removing heavy metal ions from polluted surface water with a tannin-based flocculant agent. J Hazard Mater 165:1215-1218

Ho IC, Norli I, Alkarkhi AFM, Morad N (2010) Characterization of biopolymeric flocculant (pectin) and organic synthetic flocculant (PAM): a comparative study on treatment and optimization in kaolin suspension. Bioresour Technol 101:1166-1174

Jiang J-Q, Graham NJD (1998) Pre-polymerized inorganic coagulants and phosphorus removal by coagulation - a review. Water SA 24(3):237-244

Kefala MI, Zouboulis AI, Matis KA (1999) Biosorption of cadmium ions by actinomycetes and separation by flotation. Environ Pollut 104(2):283-293

Kolya H, Tripathy T (2013) Preparation, investigation of metal ion removal and flocculation performances of grafted hydroxyethyl starch. Int J Biol Macromol 62:557-564
Mittal H, Fosso-Kankeu E, Mishra S, Mishra A (2013a) Biosorption potential of Gum ghatti-g-poly(acrylic acid) and susceptibility to biodegradation by B. subtilis. Int J Biol Macromol 62:370-378

Mittal H, Mishra SB, Mishra AK, Kaith BS, Jindal R, Kalia S (2013b) Preparation of poly(acrylamide-co-acrylic acid)-grafted gum and its flocculation and biodegradation studies. Carbohydr Polym 98:397-404

Mittal H, Jindal R, Kaith BS, Maity A, Ray SS (2014a) Synthesis and evaluation of the properties of gum ghatti and poly(acrylamideco-acrylonitrile) based biodegradable flocculants. Carbohydr Polym 114:321-329

Mittal H, Parashar V, Mishra S, Mishra A (2014b) $\mathrm{Fe}_{3} \mathrm{O}_{4}$ MNPs and gum xanthan based hydrogels nanocomposites for the efficient capture of malachite green from aqueous solution. Chem Eng J 255:471-482

Mittal H, Maity A, Ray SS (2015a) Development of gum karaya and nanosilica based hydrogel nanocomposites for the decolourization of cationic dyes. Chem Eng J 279:166-179

Mittal H, Jindal R, Kaith BS, Maity A, Ray SS (2015b) Flocculation and adsorption properties of biodegradable gum-ghatti-grafted poly(acrylamide-co-methacrylic acid) hydrogels. Carbohydr Polym 115:617-628

Peavy HS, Rowe DR, Tchobanoglous D (1985) Environmental engineering. McGraw-Hill, Singapore

Rani P, Sen G, Mishra S, Jha U (2010) Microwave assisted synthesis of polyacrylamide grafted gum ghatti and its application as flocculant. Carbohydr Polym 89:275-281

Rodriguez FJ, Cohen C, Ober C, Archer LA (2003) Principles of polymer systems, 5th edn. Taylor \& Francis, New York

Saleh TA (2015) Nanocomposite of carbon nanotubes/silica nanoparticles and their use for adsorption of $\mathrm{Pb}(\mathrm{II})$ : from surface properties to sorption mechanism. Desalin Water Treat. doi:10. 1080/19443994.2015.1036784

Saleh TA, Gupta VK (2011) Functionalization of tungsten oxide into MWCNT and its application for sunlight-induced degradation of rhodamine B. J Colloid Interface Sci 362:337-344

Saleh TA, Gupta VK (2012) Photo-catalyzed degradation of hazardous dye methyl orange by use of a composite catalyst consisting of multi-walled carbon nanotubes and titanium dioxide. J Colloid Interface Sci 371:101-106

Saleh TA, Agarwal S, Gupta VK (2011) Synthesis of MWCNT/ $\mathrm{MnO}_{2}$ and their application for simultaneous oxidation of arsenite and sorption of arsenate. Applied Catal B: Environ 106(1-2):46-53

Saravanan R, Karthikeyan S, Gupta VK, Sekaran G, Narayanan V, Stephen A (2013) Enhanced photocatalytic activity of $\mathrm{ZnO} / \mathrm{CuO}$ nanocomposite for the degradation of textile dye on visible light illumination. Mater Sci Eng, C 33:91-98

Saravanan R, Gupta VK, Mosquera E, Gracia M (2014) Preparation and characterization of $\mathrm{V}_{2} \mathrm{O}_{5} / \mathrm{ZnO}$ nanocomposite system for photocatalytic application. J Mol Liquids 198:409-412

Saravanan R, Khan MM, Gupta VK, Gracia MF, Narayanan V, Stephen A (2015) $\mathrm{ZnO} / \mathrm{Ag} / \mathrm{Mn} 2 \mathrm{O} 3$ nanocomposite for visible light-induced industrial textile effluent degradation, uric acid and ascorbic acid sensing and antimicrobial activity. RSC Adv 5:34645-34651

Singh RP, Tripathy T, Karmakar GP, Rath SK, Karmakar NC, Pandey SK, Kannan K, Jain SK, Lan NT (2000) Novel biodegradable flocculants based on polysaccharides. Curr Sci 78:798-803

Wan X, Li Y, Wang X, Chen S, Gu X (2007) Synthesis of cationic guar gum-graft-polyacrylamide at low temperature and its flocculating properties. Eur Polym J 43:3655-3661

Weiping W (2000) Tragacanth and karaya. In: Philips GO, Williams PA (eds) Handbook of hydrocolloids. Woodhead Publ Ltd, New York, pp 231-245 
Yang Z, Liu X, Gao B, Zhao S, Wang Y, Yue Q, Yang QL (2013) Flocculation kinetics and floc characteristics of dye wastewater by polyferric chloride-poly-epichlorohydrin-dimethylamine composite flocculant. Sep Purif Technol 118:583-590
Zhao YX, Gao BY, Shon HK, Cao BC, Kim J-H (2011) Coagulation characteristics of titanium (Ti) salt coagulant compared with aluminum (Al) and iron (Fe) salts. J Hazard Mater 185:1536-1542 